Article

\title{
Synthesis of PNA Oligoether Conjugates
}

Alice Ghidini ${ }^{1}$, Peter Steunenberg ${ }^{2}$, Merita Murtola ${ }^{1,3}$ and Roger Strömberg ${ }^{1, *}$

1 Department of Biosciences and Nutrition, Karolinska Institutet, Novum, Hälsovägen Huddinge 7, 14183, Sweden; E-Mails: alice.ghidini@ki.se (A.G.); merita.murtola@ki.se (M.M.)

2 ICL-IP Terneuzen, Frankrijkweg BJ, Terneuzen 6 4538, The Netherlands;

E-Mail: SteunenbergP@icl-ip.com

3 Department of Chemistry, University of Turku, Turku 20014, Finland

* Author to whom correspondence should be addressed; E-Mail: roger.stromberg@ki.se; Tel.: +46-8-5248-1024; Fax: +46-8-5248-1034.

Received: 21 January 2014; in revised form: 1 March 2014 / Accepted: 4 March 2014 / Published: 13 March 2014

\begin{abstract}
Several different approaches have been explored for conjugation of oligoethers to PNA with internally or N-terminal placed diaminopropionic acid residues. Single and double conjugation of 2-(2-(2-aminoethoxy)ethoxy)ethanol was obtained using carbonyldimidazole. Using a post PNA-assembly coupling procedure the building block 2-(2-(2-(benzoyloxy)ethoxy)ethoxy)acetic acid multiple attachment of 2-(2-(2hydroxyethoxy)ethoxy)acetyl groups to both $\mathrm{N}$-terminal and $\beta$-amino groups of inserted diaminopropionic acids residues was achieved. Use of a new oligoether functionalized amino acid allows inclusion of oligoether conjugates during on-line machine assisted synthesis which also allowed combination of methods for attachment of different oligoethers and co-conjugation of neocuproine as well as conjugation of an aminosugar.
\end{abstract}

Keywords: peptide nucleic acid; polyethyleneglycol; aminosugar; neocuproine

\section{Introduction}

Peptide nucleic acid (PNA) as first invented [1] are essentially N-(aminoethyl)glycine peptides carrying nucleic acid bases (aeg-PNA). PNA hybridizes to both DNA and RNA with Watson-Crick base pairing, thus mimicking the action of natural nucleic acids [2]. A variety of modifications of the original backbone of PNA have been reported $[3,4]$ and numerous studies directed at diagnostic use as 
well as consideration for therapeutics, has occurred over the past two decades $[5,6]$. It is not uncommon for peptides, proteins, nanoparticles, oligonucleotides and even low molecular drugs to be conjugated to polyethyleneglykol (PEG) moieties in order to enhance uptake, solubility, stability, pharmacokinetics etc. for enhanced drug delivery [7,8]. Conjugates to PNA typically involves conjugation to the carboxy or amino terminals either as exemplified for nanoparticle applications $[9,10]$ or a nucleic acids delivery construct [11]. Conjugation of shorter oligoethers to PNA is in general also to the carboxy or $\mathrm{N}$ terminal when the oligoether serves as a linker to other functionalities as in microRNA targeting PNA conjugated to a cellpenetrating peptide [12] or to the cleaver entity in a microRNA targeting PNA-based artificial nuclease [13]. An interesting example of backbone inclusion of an oligoether into a peptide nucleic acid is $\gamma$-PNA, which is a modification that involves [2-(2-methoxyethoxy)ethoxy]methyl branching of the aminoethyl moiety of aeg-PNA. This backbone modification enhances affinity for the target nucleic acid as well the solubility of the PNA in aqueous media [14].

When a duplex between two oligonucleotides contains one or several unpaired nucleotides in an internal part of one of the strands a bulge is formed (Figure 1). The occurrence of one or several bulged out nucleotides in an otherwise complementary duplex usually results in substantial destabilization of the complex [15]. Complexes with bulged out nucleotides can be stabilized by inclusion of modified nucleosides [16] or conjugation to entities that interact with the unpaired region [17]. Bulged RNA is also known to be more susceptible to cleavage than RNA in a helical structure and has been interesting as targets for 2'-O-methyloligonucleotide artificial nucleases (OBAN's) [18-20] as well as PNA-based artificial nucleases (PNAzymes) [21,22].

Figure 1. Left panel: A tetranucleotide RNA-bulge (upper case letters) formed by incomplete base pairing upon binding to a partially complementary PNA-strand (lower case letters). Right panel: A tetranucleotide RNA-bulge (upper case letters) formed upon binding to a partially complementary PNA-strand with one or two amino acids (x) incorporated.
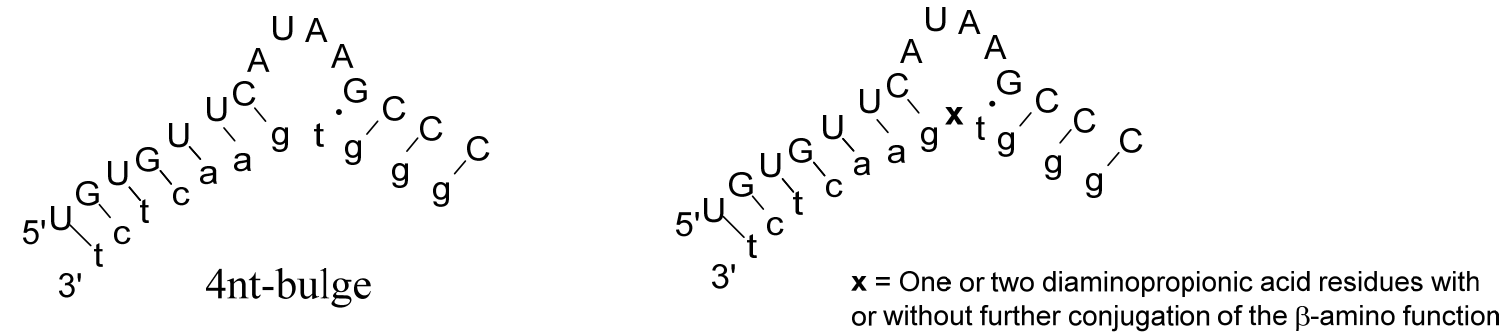

In the current study we present an investigation on the conjugation of oligoethers to PNA with internally or $\mathrm{N}$-terminal placed diaminopropionic acid residues. We were concerned how the addition of oligoethers may affect the binding of a target RNA and other properties of the PNA. In particular, we were interested to see if different oligoether constructs would hamper formation of the complex between the PNA conjugate and RNA that forms a non-paired bulge region (Figure 1) and which constructs that can be accepted in future artificial nuclease designs. Therefore several different methods and constructs were developed as reported below. In addition co-conjugation of neocuproine that has been used in artificial nucleases [18-22] is performed as well as conjugation of an aminosugar. 


\section{Results and Discussion}

The different approaches for the conjugation of oligoethers to PNA containing diaminopropionic acid (Dapa) were all performed with the PNA remaining on the solid support, where it was first assembled using Fmoc-chemistry. Prior to the post-conjugation, a 4-methyltrityl (Mtt) protecting group on the $\beta$-nitrogen of Dapa and/or the terminal Fmoc was removed. The methyltrityl (Mtt) group is acid-labile and readily removed by mild acidic treatment [23] and the amine is in situ neutralized in the subsequent conjugation reaction by adding an excess of base, such as N-Methylmorpholine (NMM) or $N, N$-Diisopropylethylamine.

First evaluated was a quick method that only involves commercial reagents, i.e., conjugation by reacting 1,1-carbonyldiimidazole (CDI, in a similar fashion as developed for oligonucleotide peptide conjugates [24]) with the Dapa $\beta$-amino group to produce intermediate PNA 1a and then add the amino-oligoether 1 to substitute the imidazole ring of the intermediate (Scheme 1). The reaction was not that effective but the product PNA 2 could be isolated by HPLC purification. Due to the incomplete conversion of PNA 1 we performed double treatment with CDI, reducing the amount of unreacted PNA but the amount of PNA 2 was not increased, instead a second product was formed that corresponds to the double substituted product PNA 3 (Scheme 1) which also could be isolated through HPLC purification.

Scheme 1. Synthesis of PNA 2 and PNA 3.

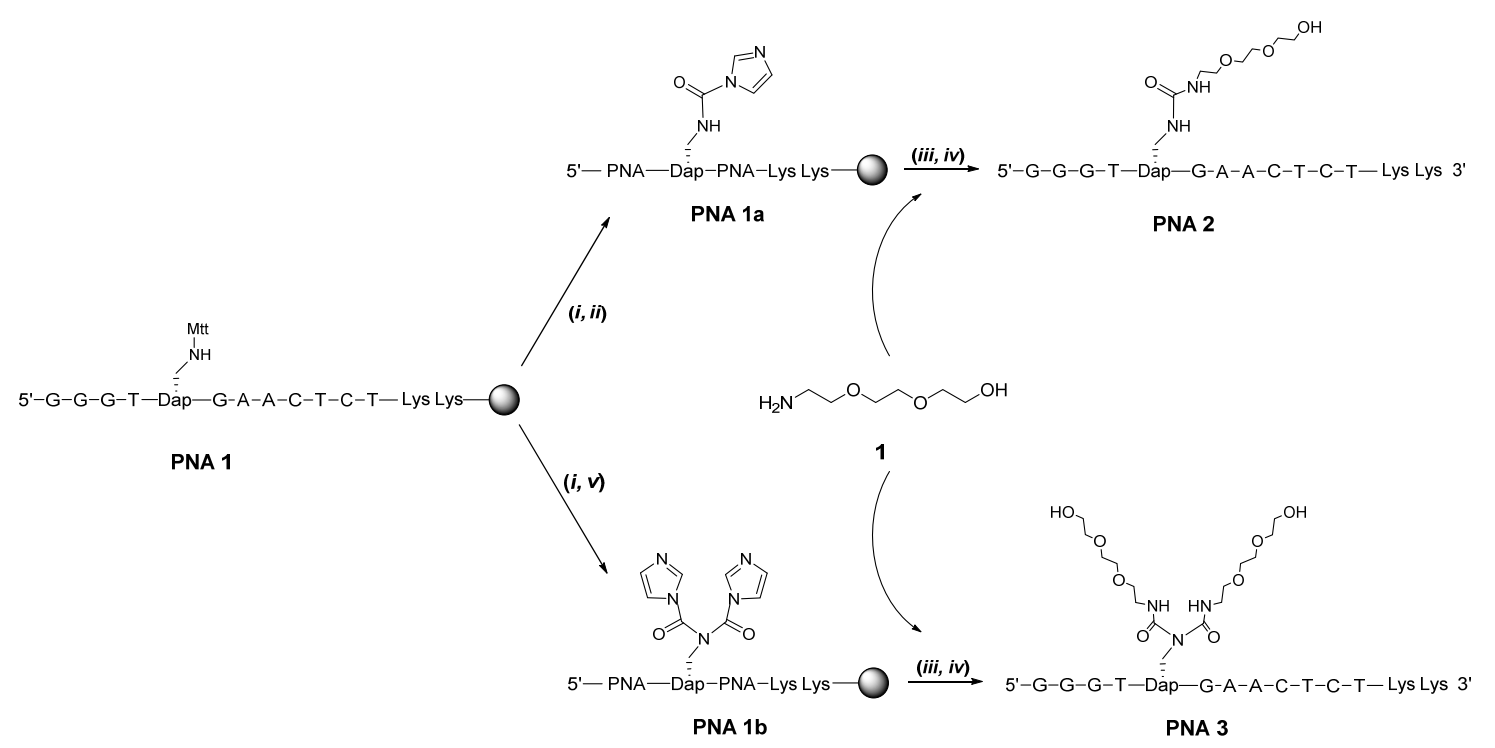

(i) $1 \%$ Trifluoroacetic acid (TFA) in DCM, 5 times for 1 min; (ii) CDI in N-Methyl-2-pyrrolidone (NMP), NMM, 1 h; (iii) oligoether 1; (iv) TFA/Triisopropylsilane (TIS)/ $\mathrm{H}_{2} \mathrm{O}(95 / 2.5 / 2.5)$ for $2 \mathrm{~h}$; (v) CDI in NMP, NMM, 1 h, 2 times.

The CDI coupling procedure did produce both a mono and double conjugation product. However, the limited conversion, and somewhat demanding purification, made this procedure less recommendable. This suggested to us that we should look at other methodologies as well. Nevertheless PNA 2 and PNA 3 were isolated so that we could evaluate if the stability of the complex with RNA that forms a bulge upon hybridization to the PNA (Figure 1, right panel) is much affected. Thermal melting analysis with the target sequence UGUGUUCAUAAGCCC revealed that the $T_{m}$ values for the 
complexes was $49{ }^{\circ} \mathrm{C}$ for both PNA 2 and PNA 3. Although this is somewhat lower compared to the complex with the non-conjugated PNA $\left(\mathrm{T}_{\mathrm{m}}=54{ }^{\circ} \mathrm{C}\right)$ of the same sequence, the oligoethers seem to be accommodated at a reasonable trade-off of $\mathrm{T}_{\mathrm{m}}$ and not interfering so severely that it would prevent association of the PNA with the RNA.

To get a method for postconjugation that was not only cleaner but also would allow multiple conjugations we then decided to utilize conditions similar to those for peptide synthesis with $\quad N, N, N^{\prime}, N^{\prime}$-tetramethyl-O-(1H-benzotriazol-1-yl)uronium hexafluorophosphate (HBTU)/1hydroxybenzotriazole hydrate (HOBt) and an oligoether carrying a carboxylate function that can be coupled to the $\beta$-amino group of Dapa and/or the N-terminal amine. To obtain conjugates with a terminal hydroxyl group on the oligoether, compound 4 was synthesized by protecting one terminal of triethylene glycol with a benzoyl group and oxidizing the other hydroxyl group to a carboxylic acid (Scheme 2A). PNA 4 was synthesized and the Mtt groups removed with the PNA still on support whereupon coupling of oligoether $\mathbf{4}$ was performed by a procedure similar to that used for coupling of amino acids to the Dapa side chain [17,25], but with reduced excess of reagent (Scheme 2B). One could remove both Fmoc and Mtt protection before conjugation to obtain the fully oligoether conjugated PNA 5. However, to verify that orthogonal functionalization could be pursued we performed the side-chain and $\alpha$-amino conjugation in separate steps.

In order to debenzoylate the oligoether the solid support was treated with $20 \% \mathrm{NH}_{3} / \mathrm{MeOH}$ solution at room temperature overnight. However, after release of the PNA from the support the chromatogram and mass spectrum of the crude material revealed that debenzoylation was incomplete. Additional deprotection of the crude material with methanolic ammonia at $50{ }^{\circ} \mathrm{C}$ for $5 \mathrm{~h}$ gave complete conversion and PNA 5 was isolated by HPLC. Also for this PNA oligoether conjugate there was an even smaller effect of the conjugation of the four oligoether groups on the stability of the complex formed with the RNA sequence UGUGUUCAUAAGCCC, than found for the products obtained with the CDI reaction (see above). Thermal melting studies gave a $\mathrm{T}_{\mathrm{m}}$ of $51^{\circ} \mathrm{C}$ for the RNA complex with PNA 5 ( $\mathrm{T}_{\mathrm{m}}$ for the RNA complex with non-conjugated PNA $\left.=54{ }^{\circ} \mathrm{C}\right)$ which suggests that there is less negative interference with the PNA/RNA complex than with the CDI linked hydroxyoligoether.

Scheme 2. Synthesis of oligoether building block 4 (A), tetraoligoether PNA conjugate

PNA 5 (B), aminosugar 7 (C) and PNA-aminosugar conjugate PNA 7 (D).

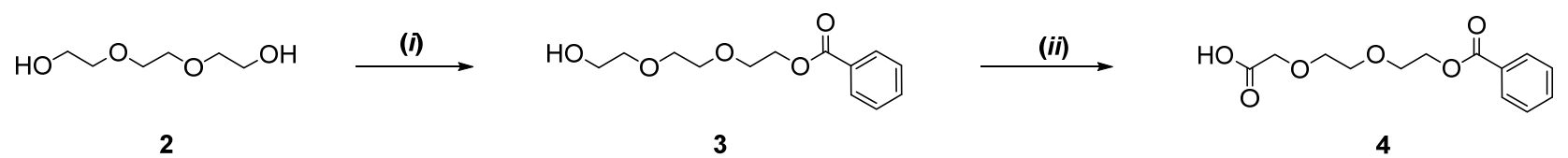

(A)

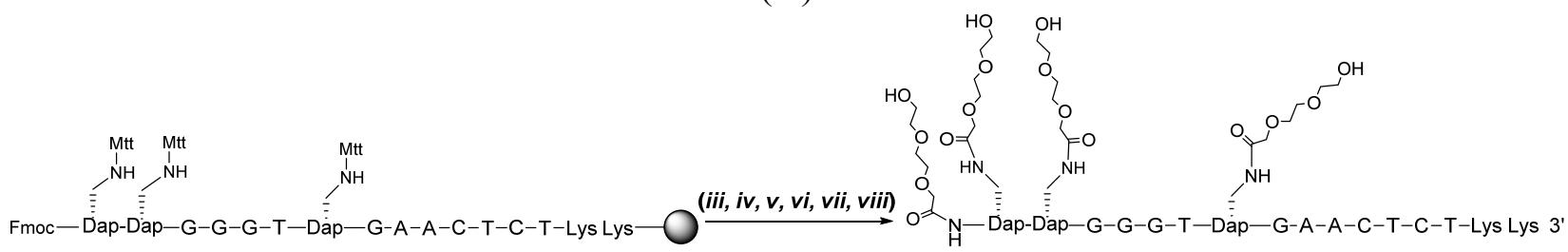

PNA 4

PNA 5

(B) 
Scheme 2. Cont.

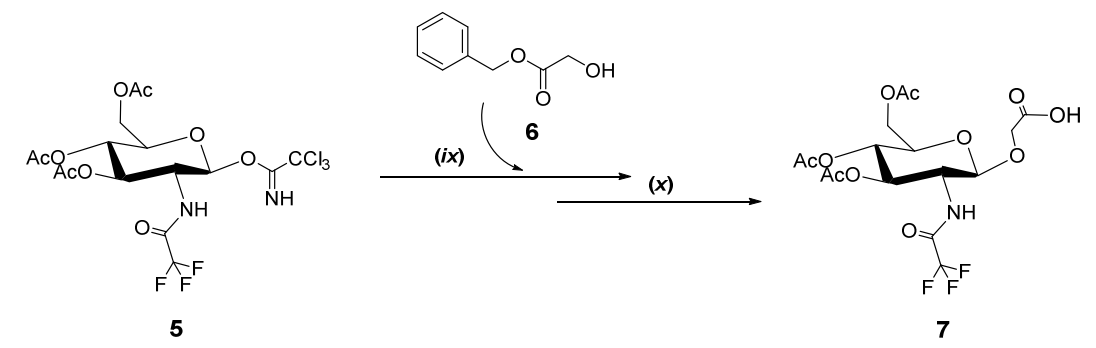

(C)

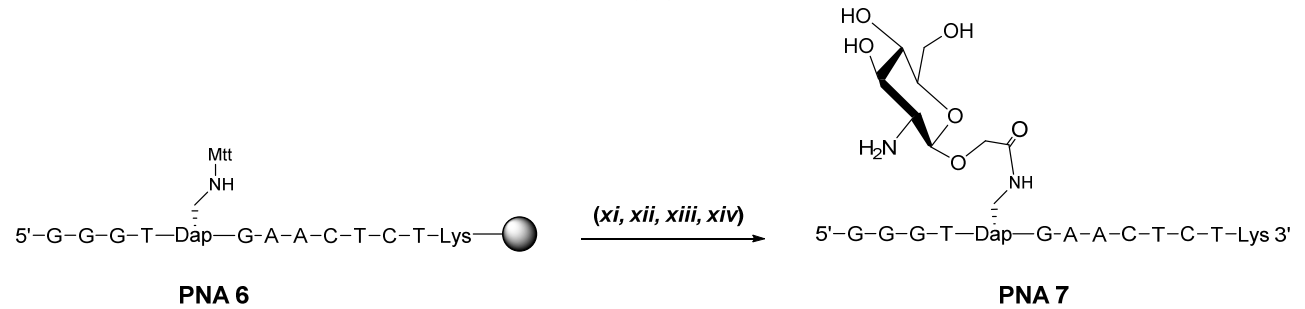

(D)

(A) (i) Triethylene glycol: Benzoyl chloride 3:1, pyridine; (ii) Acetone, $\mathrm{H}_{2} \mathrm{SO}_{4}(1.5 \mathrm{M}), \mathrm{Cr}_{2} \mathrm{O}_{3}$; (B) (iii) $20 \%$ Piperidine in NMP; (iv) oligoether 4, HBTU, HOBt, NMM; (v) 1\% TFA in DCM, 5 times for 1 min; (vi) oligoether 4, HBTU, HOBt, NMM; (vii) $20 \% \mathrm{NH}_{3} / \mathrm{MeOH}, 5 \mathrm{~h}, 50{ }^{\circ} \mathrm{C}$; (viii) TFA/TIS/H2O (95/2.5/2.5), 2 h; (C) (ix) protected glycolic acid 6, dry $\mathrm{CH}_{2} \mathrm{Cl}_{2}$, TMSOTf, from $-20{ }^{\circ} \mathrm{C}$ to room temperature, $3 \mathrm{~h}$; (x) Pd-C catalyst in THF-MeOH (1:1), overnight; and (D) (xi) 1\% TFA in DCM, 5 times for $1 \mathrm{~min}$; (xii) Aminosugar 5, HATU, DIPEA in NMP, 1h; (xiii) TFA/TIS/H2O (95/2.5/2.5) for $2 \mathrm{~h}$; (xiv) Ammonia, $5 \mathrm{~h}, 50^{\circ} \mathrm{C}$.

Another class of compounds that can be interesting to conjugate to PNA, not only for increase of aqueous solubility, is sugars and aminosugars. As an example of this, and to evaluate if PNA/RNA complex with a bulge would be affected much by the presence of sugar, we performed a conjugation to a 2-aminoglucose derivative. Compound 5 was synthesized as described with initial protection of the amino group and successive acetylation of hydroxyl groups and adding a trichloroacetimidate group in the anomeric position [26-28]. Subsequent glycosidation with a protected glycolic acid then gave product 7 [29,30]. Reacting solid supported PNA 6 with an excess of compound 7 (30 eq) and HATU as condensing agent allowed us to obtain the aminosugar conjugate PNA 7. Thermal melting studies gave a $\mathrm{T}_{\mathrm{m}}$ of $51{ }^{\circ} \mathrm{C}$ for the RNA complex with PNA 7 ( $\mathrm{T}_{\mathrm{m}}$ for the RNA complex with non-conjugated $\mathrm{PNA}=54{ }^{\circ} \mathrm{C}$ ).

In order to allow for more ready orthogonal conjugation of different groups we then turned to an alternative to post conjugation, where internal incorporation of an oligoether building block into PNA was evaluated. If this on-line approach is combined with the post-conjugations it would allow incorporation of three different conjugated entities, even though only Mtt and Fmoc temporary protection is used. To accomplish on-line incorporation we synthesized an oligoether carrying amino acid building block that can be inserted in the PNA sequence on the automated synthesizer. At the same time we also wished to see if a methoxy terminated oligoether would be accepted in PNA/RNA bulge complex. Thus, the commercially available oligoether 2-[2-(2-methoxyethoxy)ethoxy]-acetic acid (TODA) (Scheme 3A), which carries a terminal O-methyl group, was coupled with of HATU-preactivated Fmoc-L-Dab-OH (N- $\alpha$-Fmoc-L-2,4-diaminobutyric acid) to obtain the oligoether 
amino acid building block $\mathbf{8}$. The amino acid $\mathbf{8}$ was then used in the synthesis of PNA 9 that is doubly conjugated with both an oligoether and neocuproine, which in the presence of a metal ion such as $\mathrm{Zn}^{2+}$ [18-21] or $\mathrm{Cu}^{2+}$ [22] turns into an RNA cleaver. The synthesis could be achieved by a standard PNA synthesis protocol on an automated synthesizer followed by removal of the Mtt from the Dapa unit and then post conjugation with 5-phenoxycarbonylaminoneocuproine [18,19] followed by removal of Fmoc, capping, cleavage from support and deprotection. Thermal melting studies gave a $\mathrm{T}_{\mathrm{m}}$ of $52{ }^{\circ} \mathrm{C}$ for the RNA complex with PNA 9 ( $\mathrm{T}_{\mathrm{m}}$ for the RNA complex with non-conjugated PNA $=54{ }^{\circ} \mathrm{C}$ ). Thus, an oligoether in this position can be acceptable in future artificial nuclease designs without substantial compromise with regard to the stability of the PNA/RNA bulge complex.

Scheme 3. Synthesis of amino acid 8 (A), neocuproine and oligoether conjugate PNA 9 and PNA 10 (B).

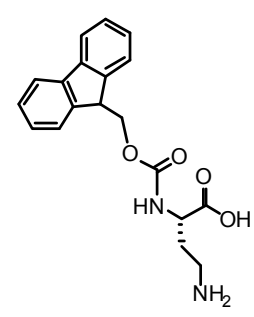

Fmoc-L-Dab-OH
(A)

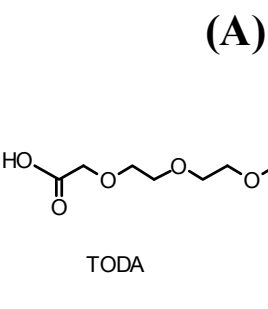

(B)

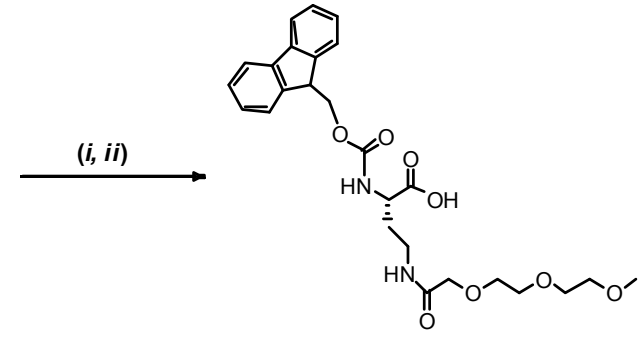

8

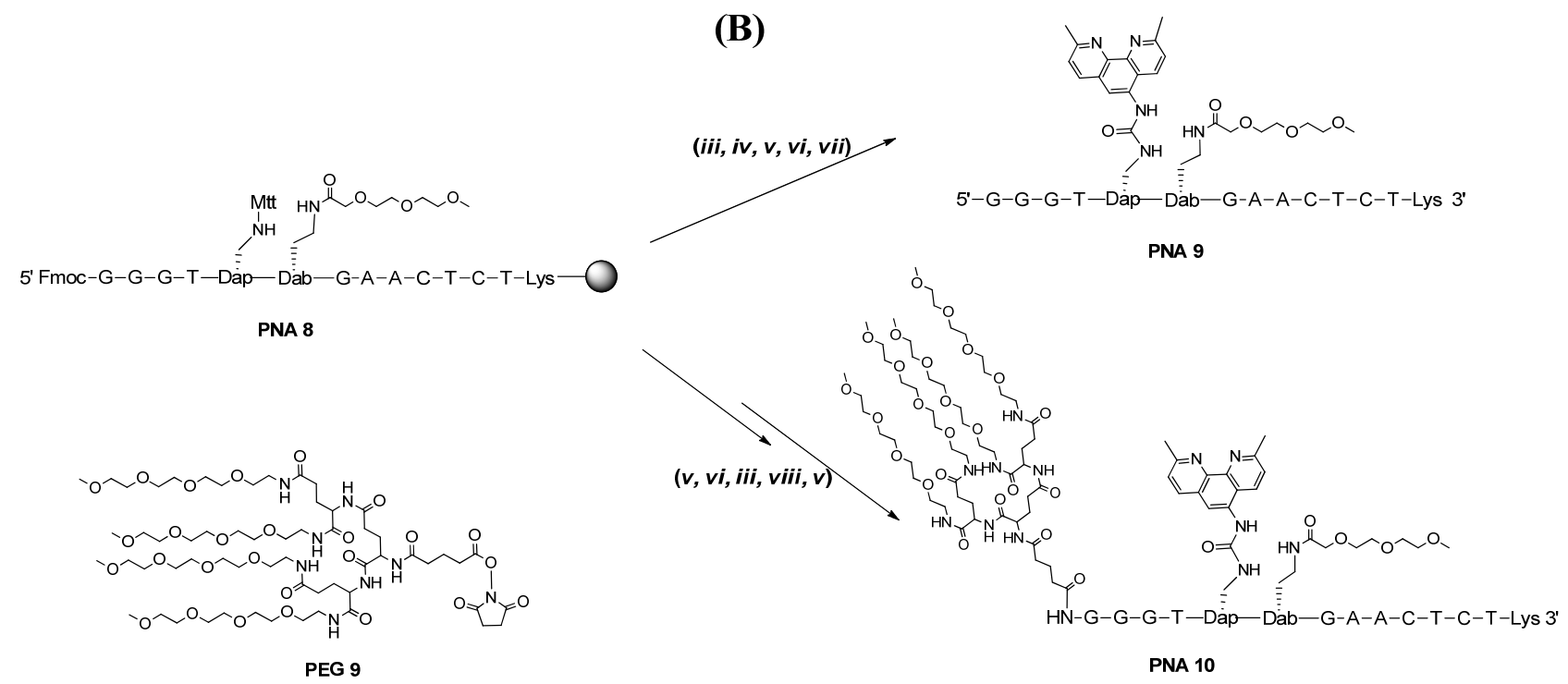

(A) (i) Preactivation of TODA with HATU, NMM in DMF (2 min); (ii) Fmoc-L-Dab-OH; (B) Synthesis of PNA 9 and PNA 10: (iii) 20\% Piperidine in NMP, $30 \mathrm{~min}$; (iv) acetic anhydride: lutidine: NMP 5:6:89 2 times for $5 \mathrm{~min}$; (v) 1\% TFA in DCM, 5 times for $1 \mathrm{~min}$; (vi) 5-PhOC(O)NH-Neocuproine, NMM in NMP overnight reaction; (vii) TFA/TIS/H2O (95/2.5/2.5) for 2 h; (viii) PEG 9, NMM, NMP.

We then wished to investigate if extensive multiple oligoether conjugation at the N-terminal would influence the stability of the complex and since the N-terminal Fmoc is orthogonal, additional complexity can be achieved by also conjugating at the amino terminal position. Thus, PNA 8 was converted to PNA 10 by reaction of the PNA with the reagent PEG 9 after removal of the Fmoc. PNA 10 was obtained but with this triply conjugated derivative carrying one neocuproine and five oligoether chains it was apparent that the solubility in water was problematic (to the extent that higher 
percentage of acetonitrile was necessary for the HPLC purification) and hence reliable thermal melting with the RNA complement could not be obtained. It appears that just addition of more oligoether chains does not necessarily give improved aqueous solubility.

In order to see if we could make sense of how the polarity was affected by oligoether conjugation we compared the RP-HPLC retention times for the conjugates and a couple of additional constructs (Table 1). PNA-Dapa-PNA 1 and PNA-Dapa-PNA 6 were obtained by complete deprotection of PNA 1 and PNA 6. These are as PNA 2 and PNA 3 or as PNA 7 respectively, but with a nonconjugated Dapa in the central position. In addition, PNA-Gly-PNA which is PNA-Dapa-PNA 6 with a glycine instead of the Dapa and PNA-GlyNeo-PNA which is as PNA 9 but with a glycine instead of the Dab-oligoether) without oligoethers were also synthesized.

Table 1. RP-18 retention times for PNA conjugates.

\begin{tabular}{|c|c|c|c|}
\hline Entry & PNA Construct & $\begin{array}{c}\text { RP-18 HPLC } \\
\text { Ret. Time (min) }{ }^{a}\end{array}$ & Type and Number of Conjugated Entities \\
\hline 1 & PNA-Dapa-PNA 1 & 13.7 & 1 Dapa \\
\hline 2 & PNA 2 & 15.7 & 1 hydroxyoligoether \\
\hline 3 & PNA 3 & 21.7 & 2 hydroxyoligoethers \\
\hline 4 & PNA 5 & 21.1 & 1 central and 3 terminal hydroxyoligoethers \\
\hline 5 & PNA-Dapa-PNA 6 & 17.7 & 1 Dapa \\
\hline 6 & PNA-Gly-PNA & 17.6 & 1 glycine \\
\hline 7 & PNA 7 & 15.8 & 1 aminosugar \\
\hline 8 & PNA-GlyNeo-PNA & 22.1 & 1 glycine and 1 neocuproine \\
\hline 9 & PNA 9 & 25.5 & 1 methoxyoligoether and 1 neocuproine \\
\hline 10 & PNA 10 & $27.9^{b}$ & $\begin{array}{l}1 \text { methoxyoligoether and } 1 \text { neocuproine and } \\
4 \text { terminal methoxyoligoethers }\end{array}$ \\
\hline
\end{tabular}

\footnotetext{
${ }^{\text {a }}$ Linear gradient of $0 \%-20 \%$ acetonitrile for $30 \mathrm{~min}$. (with $0.1 \%$ TFA) on an Ascentis Express Supelco Peptide ES-C18 $(2,7 \mu \mathrm{m} 150 \times 4.6 \mathrm{~mm})$ column at $60{ }^{\circ} \mathrm{C}$ with a flow rate of $1 \mathrm{~mL} / \mathrm{min} ;{ }^{\mathrm{b}}$ A higher percentage of acetonitrile was needed for this conjugate: Linear gradient of $7.5 \%-35 \%$ acetonitrile for 36 min. (with $0.1 \%$ TFA) on an Ascentis Express Supelco Peptide ES-C18 $(2,7 \mu \mathrm{m} 150 \times 4.6 \mathrm{~mm})$ column at $60{ }^{\circ} \mathrm{C}$ with a flow rate of $1 \mathrm{~mL} / \mathrm{min}$.
}

It is not an absolutely clear picture for these comparisons but conjugation of oligoethers seems to give a lower polarity, as judged by the shorter retention times during RP-HPLC analysis ( $c f$. entries 1 , 5, 6 and 8 with entries 2, 3, 4, 9 and 10). The only clear decrease of retention time, and presumably polarity, comes from conjugation of the aminoglucoside moiety (cf. entry 5-7).

\section{Experimental}

\subsection{Materials and Methods}

Peptide nucleic acid monomers were from Link Technologies Ltd. (Bellshill, UK). Rink Amide resin was purchased from Biotage (Uppsala, Sweden). HBTU, HOBt and diaminopropionic acid and derivatives were purchased from Novabiochem (now incorporated into Merck Millipore, Darmstadt, Germany). Solvents and reagents for solid- phase synthesis were synthesis grade from Applied Biosystems (now incorporated into Life Technologies Europe, Stockholm, Sweden) and IRIS Biotech 
Gmbh (Marktredwitz, Germany). PEG 9 was purchased from Iris Biotech Gmbh. Other solvents were purchased from Merck Eurolab (Darmstadt, Germany). High-resolution mass spectrometry (HRMS) was performed on a Micromass LCT electrospray time-of-flight (ES-TOF) mass spectrometer in acetonitrile-water 1:1 ( $/ / v)$ solutions. The molecular weights of the oligoribonucleotide and peptide nucleic acid conjugates were reconstructed from the $\mathrm{m} / \mathrm{z}$ values using the mass deconvolution program of the instrument (Mass Lynx software package). The RNA substrate was purchased from Thermoscientific and was first purified by semi-preparative IE-HPLC (ion exchange high performance liquid chromatography) and then purified with RP-HPLC. Thermal melting analysis was determined from an absorbance $v s$. temperature profile measured at $260 \mathrm{~nm}$ on a Varian Cary $300 \mathrm{UV}-\mathrm{vis}$ dual beam spectrophotometer (Varian). Concentrations of both RNA and PNA were determined by UV absorption at $260 \mathrm{~nm}$ and calculated from extinction coefficients obtained by the nearest neighbor approximation [31]. All chemicals used in the kinetics experiments were of molecular biology grade.

\subsection{Synthesis of PNAs}

PNA 1, PNA 4, PNA 6, PNA 8, PNA-Gly-PNA and PNA-GlyDapa-PNA sequences were assembled automatically on a solid support (Rink Amide resin) using the manufacturer's protocol for the Applied Biosystems 433A peptide synthesizer with 9-fluorenylmethyloxycarbonyl (Fmoc)-chemistry and HATU (1-[Bis(dimethylamino)methylene]-1H-1,2,3-triazolo[4,5-b]pyridinium 3-oxid hexafluorophosphate, from Iris Biotech) as coupling agent. PNA building blocks were from Link Technologies Ltd (Strathclyde, UK) and Fmoc- ${ }^{\alpha} \mathrm{N}-L y s$ ( $\left.{ }^{\varepsilon} \mathrm{N}-\mathrm{Boc}\right) \mathrm{OH}$ was from Iris Biotech Gmbh (Marktredwitz, Germany). PNAs were purified with an Ascentis Express Supelco Peptide ES-C18 $(2,7 \mu \mathrm{m} 150 \times 4.6 \mathrm{~mm})$ column at $60{ }^{\circ} \mathrm{C}$ using a flow rate of $1 \mathrm{~mL} / \mathrm{min}$ and a linear gradient of $40 \% \mathrm{~B}$ for $30 \mathrm{~min}$. (A) $0.1 \%$ TFA-aq., (B) $0.1 \%$ TFA-aq., 50\% MeCN.

PNA-Dapa-PNA 1 and PNA-Dapa-PNA 6 conjugates were obtained by cleaving PNA 1 and PNA 6, respectively, from support by TFA/TIS/water (95/2.5/2.5) $(200 \mu \mathrm{L})$ for $2 \mathrm{~h}$. Products were freeze dried and purified on an Ascentis Express Supelco Peptide ES-C18 $(2,7 \mu \mathrm{m} 150 \times 4.6 \mathrm{~mm})$ column at $60{ }^{\circ} \mathrm{C}$ using a flow rate of $1 \mathrm{~mL} / \mathrm{min}$ and a linear gradient of $40 \% \mathrm{~B}$ for $30 \mathrm{~min}$. (A) $0.1 \% \mathrm{TFA}$-aq., (B) $0.1 \%$ TFA-aq., 50\% MeCN. (Retention time PNA-Dapa-PNA 1: $13.7 \mathrm{~min}$ and PNA-Dapa-PNA 6: 17.7 min). PNA-Dapa-PNA 1: C136H181N71O38 [M+], 3418; found, 3418 and PNA-Dapa-PNA 6: C129H166N68O37, 3259; found [M+] 3260.

PNA-Gly-PNA was obtained cleaving from support by TFA/TIS/water (95/2.5/2.5) $(200 \mu \mathrm{L})$ for $2 \mathrm{~h}$, freeze dried and purified with a Ascentis Express Supelco Peptide ES-C18 (2, $7 \mu \mathrm{m} 150 \times 4.6 \mathrm{~mm})$ column at $60{ }^{\circ} \mathrm{C}$ using a flow rate of $1 \mathrm{~mL} / \mathrm{min}$ and a linear gradient of $40 \% \mathrm{~B}$ for $30 \mathrm{~min}$. (A) $0.1 \%$ TFA-aq., (B) 0.1\% TFA-aq., 50\% MeCN. (Retention time PNA-Gly-PNA 1: $17.6 \mathrm{~min}$ ). PNA-GlyPNA: C129H166N68O37, 3259; found [M+] 3260.

\subsection{Post-Conjugation of Oligoethers to PNA}

Synthesis of PNA 2 and PNA 3. $\mathrm{N}^{\beta}$-methyltrityl protection was cleaved off by subjecting the solid support bound PNA $1(1.4 \mu \mathrm{mol})$ to $1 \%$ trifluoroacetic acid (TFA) in dichloromethane (DCM) for $5 \times 1 \mathrm{~min}$, followed by washing with DCM and NMP. CDI (1, 1'-Carbonyldiimidazole) $(0.014 \mathrm{mmol}$, $10 \mathrm{eq})$ was dissolved in NMP $(150 \mu \mathrm{L})$ in a septum capped vial and NMM (4-Methylmorpholine) 
( $0.071 \mathrm{mmol}, 50 \mathrm{eq}$ ) was added to the solution. The mixture was added to the support bound PNA 1 through a septum and the reaction mixture was agitated for $1 \mathrm{~h}$. The support was filtered but not washed. Polyether $1(0.71 \mathrm{mmol})$ was then dissolved in NMP $(150 \mu \mathrm{L})$ and added to the same support with $40 \mu \mathrm{L}$ of NMM and shaken overnight. The support was filtered and washed with NMP and DCM.

PNA 3 was obtained when the CDI treatment was repeated twice and otherwise following the procedure for the oligoether 1 coupling as when isolating PNA 2.

The PNA conjugates were cleaved from support by TFA/TIS/water $(95 / 2.5 / 2.5)(200 \mu \mathrm{L})$ for $2 \mathrm{~h}$, freeze dried and purified with a Ascentis Express Supelco Peptide ES-C18 $(2,7 \mu \mathrm{m} 150 \times 4.6 \mathrm{~mm})$ column at $60{ }^{\circ} \mathrm{C}$ using a flow rate of $1 \mathrm{~mL} / \mathrm{min}$ and a linear gradient of $40 \% \mathrm{~B}$ for $30 \mathrm{~min}$. (A) $0.1 \%$ TFA-aq., (B) 0.1\% TFA-aq., 50\% MeCN. (Retention time PNA 2: $15.7 \mathrm{~min}$ and PNA 3: $21.7 \mathrm{~min}$ ). PNA 2: C143H194N72O42 [M+], 3591; found, 3590 and PNA 3: C150H207N73O46, 3767; found $[\mathrm{M}+] 3769$.

Synthesis of 2-(2-(2-hydroxyethoxy)ethoxy)ethyl benzoate (3). Triethylene glycol (3 mL, 3 eq, $30 \mathrm{mmol})$ was twice dried by evaporation of added pyridine $(20 \mathrm{~mL})$. The residue was dissolved in pyridine $(40 \mathrm{~mL})$ and benzoyl chloride $(1.2 \mathrm{~mL}, 1 \mathrm{eq}, 10 \mathrm{mmol})$ was then added dropwise to the dry solution at $0{ }^{\circ} \mathrm{C}$ and at an interval of $10 \mathrm{~min}$. After complete addition, the solution was allowed to obtain room temperature and the reaction was monitored by TLC. After $2 \mathrm{~h}$ most of the reagent was converted and the reaction was stopped by adding $5 \mathrm{~mL}$ of water and the pyridine was evaporated in the presence of added acetonitrile. The crude material was dissolved in toluene and washed with $\mathrm{NaHCO}_{3}$ to remove excess of the diol and the organic phase was dried over magnesium sulfate. The product was isolated by flash chromatography on a column of silica gel using gradient hexane in ethyl acetate giving 1,02 $\mathrm{g}$ of $\mathbf{3}$ (40\%). Mass calculated for compound 3, 254.12; found, [M+23(Na)] 277.46; 1H-NMR (CDCl3): $\delta$ $8.06(\mathrm{~d}, 2 \mathrm{H}, J=8) ; \delta 7.56(\mathrm{t}, 1 \mathrm{H}, J=7.4) ; \delta 7.44(\mathrm{t}, 2 \mathrm{H}, J=7.6) ; \delta 4.50(\mathrm{t}, 2 \mathrm{H}, J=4.7) ; \delta 3.84(\mathrm{t}, 2 \mathrm{H}$, $J=5.1) ; \delta 3.87(\mathrm{~m}, 6 \mathrm{H}) ; \delta 3.61(\mathrm{t}, 2 \mathrm{H}, J=4.6)$.

Synthesis of 2-(2-(2-(benzoyloxy)ethoxy)ethoxy)acetic acid (4). Compound 3 (0.30 g, $1.2 \mathrm{mmol})$ was dissolved in acetone $(6 \mathrm{~mL})$ and added dropwise to a solution of sulfuric acid (1.5 M, 7.2 $\mathrm{mL}$ ) containing chromium (VI) oxide $(0.41 \mathrm{~g}, 4.1 \mathrm{mmol})$ at $0{ }^{\circ} \mathrm{C}$. After complete addition of the alcohol, the solution was kept at room temperature for $24 \mathrm{~h}$. The chromium salts were removed by steps of filtrations and centrifugations and the clear solution was concentrated under reduce pressure. The crude material was extracted from the solution using toluene $(3 \times 40 \mathrm{~mL})$ and dried over magnesium sulfate. After filtration and concentration, the crude oil product was purified using column chromatography on silica eluted with a gradient system running from pure dichloromethane with $1 \%$ acetic acid to dichloromethane $90 \%$ methanol $10 \%$ with $1 \%$ acetic acid. This gave the product as yellow oil (167 mg). Mass calculated for compound 4, 268.09; found, [M+23(Na)] 291.49; ${ }^{1} \mathrm{H}-\mathrm{NMR}$ $\left(\mathrm{CDCl}_{3}\right): \delta 8.06(\mathrm{~d}, 2 \mathrm{H}, J=7.5) ; \delta 7.56(\mathrm{t}, 1 \mathrm{H}, J=7.5) ; \delta 7.44(\mathrm{t}, 2 \mathrm{H}, J=7.5) ; \delta 4.52(\mathrm{t}, 2 \mathrm{H}, J=3.9)$; $\delta 4.17(\mathrm{~s}, 2 \mathrm{H}) ; \delta 3.87$ (t, 2H, $J=4.8) ; \delta 3.76$ (q, 2H, $J=5.4) ;{ }^{13} \mathrm{C}-\mathrm{NMR}(\mathrm{CDCl} 3): \delta 171.61 .0 ; \delta 165.55$; $\delta 132.10 ; \delta 128.89 ; \delta 128.76 ; \delta 127.39 ; \delta 76.32 ; \delta 76.00 ; \delta 75.69 ; \delta 67.61 ; \delta 62.69$.

Synthesis of PNA 5. The terminal Fmoc was cleaved off by subjecting PNA 4 (4 mg, $1.13 \mu \mathrm{mol}$ ) to $20 \%$ piperidine in NMP for $25 \mathrm{~min}$, followed by washing several times with DCM and NMP. 
Compound 4 (11.4 mg, $37.5 \mathrm{eq}$ ), HBTU (15.3 mg, $35.6 \mathrm{eq}$ ) and HOBt (5.4 mg, $35.6 \mathrm{eq}$ ) were dissolved in $97.5 \mu \mathrm{L}$ of NMP and NMM $(8.25 \mu \mathrm{L}, 65 \mathrm{eq})$ and agitated for 5 min to preactivate the mixture, then added to the solid support and shaken for $30 \mathrm{~min}$. The support was filtered and washed with NMP and DCM. The $\mathrm{N}^{\beta}$-methyltrityl protection of the diaminopropionic acid was removed by subjecting the solid support to $1 \%$ trifluoroacetic acid (TFA) in dichloromethane (DCM) for $5 \times 1 \mathrm{~min}$, followed by washing with DCM and NMP. Compound 4 (34.2 mg, $112.5 \mathrm{eq}$ ), HBTU (45.9 mg, $106.8 \mathrm{eq}$ ) and HOBt (16.2 mg, $106.8 \mathrm{eq})$ were dissolved in $318 \mu \mathrm{L}$ of NMP and NMM (25.5 $\mu \mathrm{L}, 195 \mathrm{eq})$ were added before agitation for $5 \mathrm{~min}$. The preactivated mixture was added to the support and shaken for 30 min. The support was filtered and washed with NMP and DCM. The PNA conjugate was deprotected using a $20 \% \mathrm{NH} 3 / \mathrm{MeOH}$ solution for $5 \mathrm{~h}$ at $50{ }^{\circ} \mathrm{C}$ and cleaved from support by TFA/TIS/water (95/2.5/2.5) $(200 \mu \mathrm{L})$ for $2 \mathrm{~h}$, freeze dried and purified as for PNA 2 (Retention time PNA 5: $21.1 \mathrm{~min})$. Mass calculated for PNA 5: C164H231N75O55, 4131; found, [M+] 4131.

Synthesis of (7). To a solution of anhydrous $\mathrm{CH}_{2} \mathrm{Cl}_{2}(3 \mathrm{~mL}), 4 \AA$ mol. sieves $(0.1 \mathrm{~g})$, protected glycolic acid 6 (150 g, $0.91 \mathrm{mmol}$ ) and compound 5 (500 g, $0.91 \mathrm{mmol})$ was added, at $-20{ }^{\circ} \mathrm{C}$ under argon atmosphere, TMSOTf $(15 \mu \mathrm{L}, 0,075 \mathrm{mmol})$. Afterwards the reaction mixture was stirred at this temperature for $3 \mathrm{~h}$ until TLC showed full conversion (PE:EtOAc 7:3, Rf 0.3). Than the mixture was quenched by the addition of $\mathrm{Et}_{3} \mathrm{~N}$, filtered and the residue washed with $\mathrm{CH}_{2} \mathrm{Cl}_{2}(100 \mathrm{~mL})$. The organic layer was concentrated. Pd-C catalyst was added to a solution of the oily mixture obtained from the previous reaction in $75 \mathrm{~mL}$ of (1:1) THF-MeOH. Afterwards, under stirring, the reaction mixture was placed under an $\mathrm{H}_{2}$ gas atmosphere (atmospheric pressure) and the deprotection of the benzyl ester was continued overnight. When full conversion had taken place (TLC examination), the $\mathrm{H}_{2}$ flow was replaced by Argon and the reaction mixture was filtered and washed $(\mathrm{MeOH}, 200 \mathrm{~mL})$ through a pad of Celite. Upon concentration of the filtrate, a white solid material was obtained, and added $\mathrm{CH}_{2} \mathrm{Cl}_{2}$ was evaporated to remove traces of $\mathrm{MeOH}$ to afford 7 as a white solid (274 g, $0.6 \mathrm{mmol}, 65 \%$ yield). Mass calculated for compound 7, 459.10; found [M-] 458; $1 \mathrm{H}-\mathrm{NMR}\left(\mathrm{DMSO}-\mathrm{d}_{6}\right): \delta 6.26(1 \mathrm{H}, \mathrm{NH}) ; \delta$ $5.18(1 \mathrm{H}, \mathrm{t}, J=10) ; \delta 4.81(1 \mathrm{H}, \mathrm{t}, J=10) ; \delta 4.73(1 \mathrm{H}, \mathrm{d}, J=8.4) ; \delta 4.15-4.04(2 \mathrm{H}, \mathrm{m}) ; \delta 3.93(2 \mathrm{H}, \mathrm{s}$, $J=2.4) ; \delta 3.82-3.72(2 \mathrm{H}, \mathrm{m}) ; \delta 1.98(3 \mathrm{H}, \mathrm{s}) ; \delta 1.87(3 \mathrm{H}, \mathrm{s}) ; \delta 1.83(3 \mathrm{H}, \mathrm{s}) ; .{ }^{13} \mathrm{C}-\mathrm{NMR}$ (DMSO-d6): $\delta$ $171.1-169.3(3 \mathrm{COCH} 3$ and $1 \mathrm{COOH}) ; \delta 157.60 ; \delta 114.2 ; \delta 99.6 ; \delta 77.0 ; \delta 72.1 ; \delta 70.6 ; \delta 65.3 ; \delta 62.0$; $\delta 54.0 ; \delta 20.68 ; \delta 20.65 ; \delta 20.48$.

Synthesis of PNA 7. The $\mathrm{N}^{\beta}$-methyltrityl protection of the diaminopropionic acid was removed subjecting the solid support PNA 6 to $1 \%$ trifluoroacetic acid (TFA) in dichloromethane (DCM) for $5 \times 1 \mathrm{~min}$, followed by washing with DCM and NMP. Compound 7 (5.8 mg, $30 \mathrm{eq}$ ), HATU (4.3 mg, $27 \mathrm{eq})$ were dissolved in $100 \mu \mathrm{L}$ of NMP and $2 \mu \mathrm{L}$ of DIPEA and agitated for $1 \mathrm{~min}$. The preactivated mixture was added to the support and shaken for $1 \mathrm{~h}$. The support was filtered and washed with NMP and DCM. The PNA conjugate was cleaved from support by TFA/TIS/water (95/2.5/2.5) (200 $\mu \mathrm{L})$ for $2 \mathrm{~h}$ and the carbohydrate protecting groups were removed using ammonia solution for $5 \mathrm{~h}$ at $50{ }^{\circ} \mathrm{C}$. The mixture was then lyophilized and purified as described for PNA 2 (Retention time PNA 7: $15.8 \mathrm{~min}$ ). Mass calculated for PNA 7: C138H183N71O42, 3507; found, [M+] 3508. 


\subsection{Introduction of a New Amino Acid Building Block in the PNA Sequence}

Synthesis of PNA-GlyNeo-PNA. $\mathrm{N}^{\beta}$-methyltrityl protection was cleaved off by subjecting the solid supported PNA-GlyDapa-PNA to $1 \%$ trifluoroacetic acid in DCM for $5 \times 1 \mathrm{~min}$, followed by washing with DCM and NMP. Then 5-phenoxycarbonylamino-2,9-dimethyl-1,10- phenanthroline (3.1 mg, $9 \mu \mathrm{mol})$, NMM $(5 \mu \mathrm{L}, 50 \mu \mathrm{mol})$ in NMP $(75 \mu \mathrm{L})$ was added to the support. The reaction was left overnight. After washing with NMP and DCM, the PNA conjugate was cleaved from support by TFA/TIS/water (95/2.5/2.5) (200 $\mu \mathrm{L})$ for $2 \mathrm{~h}$, freeze dried and purified (Retention time PNA-GlyNeo-PNA : $22.1 \mathrm{~min}$ ). Mass calculated for PNA-GlyNeo-PNA: C147H183N73O39, 3595; found, [M+] 3597.

Synthesis of (8). 2-(2-(2-methoxyethoxy)ethoxy]acetic acid (109 $\mu \mathrm{L}, 0.7 \mathrm{mmol}, 1.2 \mathrm{eq})$ and HATU $(1.1 \mathrm{~g}, 1.9 \mathrm{eq})$ were dissolved in $2 \mathrm{~mL}$ of DMF and stirred for $2 \mathrm{~min}$ in presence of $0.5 \mathrm{eq}$ of NMM and then added to Fmoc-L-Dab-OH $(200 \mathrm{mg}, 0.58 \mathrm{mmol})$ previously suspended in $7 \mathrm{~mL}$ of DMF. The reaction was run at room temperature for $20 \mathrm{~min}$. The solution was dried and purified using column chromatography on silica eluted with a gradient system running from pure dichloromethane with $1 \%$ acetic acid to dichloromethane $90 \%$ methanol $15 \%$ with $0.1 \%$ acetic acid. This gave the product as 181 mg of a yellow oil. Mass calculated for compound $8[\mathrm{M}+], 500.54$; found, $[\mathrm{M}+]$ 501.6; ${ }^{1} \mathrm{H}-\mathrm{NMR}$ $\left(\mathrm{CD}_{3} \mathrm{OD}\right): \delta 7.82(\mathrm{~d}, 2 \mathrm{H}, J=7.5) ; \delta 7.71(\mathrm{t}, 2 \mathrm{H}, J=6.6) ; \delta 7.41(\mathrm{t}, 2 \mathrm{H}, J=7.4) ; \delta 7.34(\mathrm{t}, 2 \mathrm{H}, J=7.4)$; $\delta 4.40(\mathrm{~d}, 2 \mathrm{H}, J=6.3) ; \delta 4.30-4.19(\mathrm{~m}, 2 \mathrm{H}) ; \delta 4.00(\mathrm{~s}, 2 \mathrm{H}) ; \delta 3.69-3.53(\mathrm{~m}, 8 \mathrm{H}) ; \delta 3.39(\mathrm{~s}, 1 \mathrm{H}) ; \delta 3.35$ $(\mathrm{s}, 3 \mathrm{H}) ; \delta 3.33(\mathrm{~s}, 1 \mathrm{H}) \delta 2.17-2.04(\mathrm{~m}, 1 \mathrm{H}) ; \delta 1.92-1.79(\mathrm{~m}, 1 \mathrm{H}) ; 13 \mathrm{C}-\mathrm{NMR}\left(\mathrm{CD}_{3} \mathrm{OD}\right): \delta 173.43 ; \delta$ $159.10 ; \delta 145.77 ; \delta 129.20 ; \delta 128.60 ; \delta 126.70 ; \delta 121.33 ; \delta 73.26 ; \delta 72.42 ; \delta 71.70 ; \delta 71.58 ; \delta 69.81 ; \delta$ $68.22 ; \delta 59.46 ; \delta 53.92 ; \delta 48.77 ; \delta 37.16 ; \delta 32.73$.

Synthesis of PNA 9. The terminal Fmoc was cleaved off by subjecting PNA 8 (5 mg, $1.04 \mu \mathrm{mol})$ to $20 \%$ piperidine in NMP for 25 min, followed by washing several times with DCM and NMP and the terminal amino group was acetylated using a solution of acetic anhydride: lutidine: NMP, 5: 6: 89 $(2 \times 5 \mathrm{~min})$. The support was filtered and washed with NMP and DCM. $\mathrm{N}^{\beta}$-methyltrityl protection was cleaved off by subjecting the solid support to $1 \%$ trifluoroacetic acid in DCM for $5 \times 1 \mathrm{~min}$, followed by washing with DCM and NMP then 5-phenoxycarbonylamino-2,9-dimethyl-1,10- phenanthroline (3.1 mg, $9 \mu \mathrm{mol})$, NMM $(5 \mu \mathrm{L}, 50 \mu \mathrm{mol})$ and NMP $(75 \mu \mathrm{L})$ were added to the support. The reaction was left overnight. The PNA conjugate was cleaved from support by TFA/TIS/water (95/2.5/2.5) $(200 \mu \mathrm{L})$ for $2 \mathrm{~h}$, freeze dried and purified (Retention time PNA 9: $25.5 \mathrm{~min}$ ). Mass calculated for PNA 9: C156H200N74O43, 3798; found, [M+] 3800.

Synthesis of PNA 10. The terminal Fmoc was cleaved off by subjecting PNA 8 (5 mg, $1.04 \mu \mathrm{mol}$ ) to $20 \%$ piperidine in NMP for $25 \mathrm{~min}$, followed by washing several times with DCM and NMP and then coupled with PEG $9(8 \mathrm{mg}, 5.8 \mu \mathrm{mol})$ in NMP $(75 \mu \mathrm{L})$ with NMM $(50 \mu \mathrm{mol}, 5 \mu \mathrm{L})$ was added to the support. The reaction was left overnight. The support was then filtered and washed with NMP and DCM. $\mathrm{N}^{\beta}$-methyltrityl protection was cleaved off by subjecting the solid support to $1 \%$ trifluoroacetic acid in DCM for $5 \times 1 \mathrm{~min}$, followed by washing with DCM and NMP then 5-phenoxycarbonylamino2,9-dimethyl-1,10- phenanthroline (3.1 mg, $9 \mu \mathrm{mol})$, NMM $(50 \mu \mathrm{mol}, 5 \mu \mathrm{L})$ and NMP $(75 \mu \mathrm{L})$ were added to the support. The reaction was left overnight. 
The PNA conjugate was cleaved from support by TFA/TIS/water $(95 / 2.5 / 2.5)(200 \mu \mathrm{L})$ for $2 \mathrm{~h}$, freeze dried and purified with a Ascentis Express Supelco Peptide ES-C18 $(2,7 \mu \mathrm{m} 150 \times 4.6 \mathrm{~mm})$ column at $60{ }^{\circ} \mathrm{C}$ using a flow rate of $1 \mathrm{~mL} / \mathrm{min}$ and a linear gradient of $20 \%-100 \%$ B for $38 \mathrm{~min}$. (A) $0.1 \%$ TFA-aq., (B) $0.1 \%$ TFA-aq., 50\% MeCN (Retention time PNA 10: 27.9 min). Mass calculated for PNA 10: C210H301N81O66, 5013; found, [M+] 5014.

\section{Conclusions}

We have in this study demonstrated synthesis and approaches to PNA conjugated to different oligoethers, an aminosugar and attachment of one or two different oligoether entities together with a neocuproine derivative. The thermal melting is somewhat affected upon central positioning of the oligoethers but this seems to be at an acceptable level for use of the conjugates. It is less clear how the polarity of the conjugates is affected by addition of oligoethers (as judged from RP-HPLC retention) and it is likely that how and where these are attached as well as the exact nature of the conjugated entities play a role. Conjugation of oligoethers to PNA is in its infancy and is likely to influence solubility and other properties of the PNA, perhaps also catalytic activity of PNAzymes and further studies will reveal such influences.

\section{Supplementary Materials}

Supplementary materials can be accessed at: http://www.mdpi.com/1420-3049/19/3/3135/s1.

\section{Acknowledgments}

We greatly appreciate funding from the Swedish Science research council and the European 7 th framework program.

\section{Conflicts of Interest}

The authors declare no conflict of interest.

\section{References}

1. Nielsen, P.E.; Egholm, M.; Berg, R.H.; Buchardt, O. Sequence-selective recognition of DNA by strand displacement with a thymine-substituted polyamide. Science 1991, 254, 1497-1500.

2. Nielsen, P.E. Peptide nucleic acid. A molecule with two identities. Acc. Chem. Res. 1999, 32, 624-630.

3. Ganesh, K.N.; Nielsen, P.E. Peptide nucleic acids: Analogs and derivatives. Curr. Org. Chem. 2000, 4, 931-943.

4. Rozners, E. Recent advances in chemical modification of peptide nucleic acids. J. Nucleic Acids 2012, doi:10.1155/2012/518162.

5. Lundin, K.E.; Good, L.; Strömberg, R.; Gräslund, A.; Smith, C.I.E. Biological activity and biotechnological aspects of peptide nucleic acid. Adv. Genet. 2006, 56, 1-51.

6. Nielsen, P.E. Peptide nucleic acids (PNA) in chemical biology and drug discovery. Chem. Biodivers. 2010, 7, 786-804. 
7. Greenwald, R.B.; Choe, Y.H.; McGuire, J.; Conover, C.D. Effective drug delivery by PEGylated drug conjugates. Adv. Drug Deliver. Rev. 2003, 55, 217-250.

8. Ryan, S.M.; Mantovani, G.; Wang, X.; Haddleton, D.M.; Brayden, D.J. Advances in PEGylation of important biotech molecules: Delivery aspects. Expert Opin. Drug Del. 2008, 5, 371-383.

9. Dettin, M.; Silvestri, D.; Danesin, R.; Cretaio, E.; Picariello, G.; Casarin, E.; Sonato, A.; Romanato, F.; Morpurgo, M. Synthesis and chromatography-free purification of PNA-PEO conjugates for the functionalisation of gold sensors. Molecules 2012, 17, 11026-11045.

10. Zhang, Z.; Liu, Y.; Jarreau, C.; Welch, M.J.; Taylor, J.-S.A. Nucleic acid-directed self-assembly of multifunctional gold nanoparticle imaging agents. Biomater. Sci. 2013, 1, 1055-1064.

11. Millili, P.G.; Yin, D.H.; Fan, H.; Naik, U.P.; O’Sullivan, M. Formulation of a peptide nucleic acid based nucleic acid delivery construct. Bioconjugate Chem. 2010, 21, 445-455.

12. Brown, P.N.; Yin, H. PNA-based microRNA inhibitors elicit anti-inflammatory effects in microglia cells. Chem. Commun. 2013, 49, 4415-4417.

13. Gaglione, M.; Milano, G.; Chambery, A.; Moggio, L.; Romanelli, A.; Messere, A. PNA-based artificial nucleases as antisense and anti-miRNA oligonucleotide agents. Mol. Biosystem. 2011, 7 , 2490-2499.

14. Sahu, B.; Sacui, I.; Rapireddy, S.; Zanotti, K.J.; Bahal, R.; Armitage, B.A.; Ly, D.H. Synthesis and characterization of conformationally preorganized, (r)-diethylene glycol-containing $\gamma$-peptide nucleic acids with superior hybridization properties and water solubility. J. Org. Chem. 2011, 76, 5614-5627.

15. Nelson, J.W.; Martin, F.H.; Tinoco, I., Jr. DNA and RNA oligomer thermodynamics: The effect of mismatched bases on double-helix stability. Biopolymers 1981, 20, 2509-2531.

16. Madder, A.; Ehrl, R.; Strömberg, R. Stabilization of RNA bulges by oligonucleotide complements containing an adenosine analogue. ChemBioChem 2003, 4, 1194-1200.

17. Sandbrink, J.; Ossipov, D.; Åström, H.; Strömberg, R. Investigation of potential RNA bulge stabilizing elements. J. Mol. Recognit. 2005, 18, 318-326.

18. Åström, H.; Williams, N.H.; Strömberg, R. Oligonucleotide based artificial nuclease (OBAN) systems. Bulge size dependence and positioning of catalytic group in cleavage of RNA-bulges. Org. Biomol. Chem. 2003, 1, 1461-1465.

19. Åström, H.; Strömberg, R. Synthesis of new OBAN's and further studies on positioning of the catalytic group. Org. Biomol. Chem. 2004, 2, 1901-1907.

20. Murtola, M.; Strömberg, R. 2'-O-Methyloligoribonucleotide based artificial nucleases (2'-OMeOBANs) cleaving a model of the leukemia related m-bcr/abl m-RNA. ARKIVOC 2008, 3, 84-94.

21. Murtola, M.; Strömberg, R. PNA based artificial nucleases displaying catalysis with turnover in the cleavage of a leukemia related RNA model. Org. Biomol. Chem. 2008, 6, 3837-3842.

22. Murtola, M.; Wenska, M.; Strömberg, R. PNAzymes that are artificial RNA restriction enzymes. J. Am. Chem. Soc. 2010, 132, 8984-8990.

23. Bourel, L.; Carion, O.; Gras-Masse, H.; Melnyk, O. The deprotection of Lys (Mtt) Revisited. J. Pept. Sci. 2000, 6, 264-270.

24. Kaneno, J.; Kubo, T.; Fujii, M. Synthesis of DNA-peptide conjugates by solid phase fragment condensation. J. Pept. Sci. 2002, 38, 339-342. 
25. Sandbrink, S.; Murtola, M.; Strömberg, R. Solid support post-conjugation of amino acids and a phenanthroline derivative to a central position in peptide nucleic acids. Nucleos. Nucleot. Nucl. 2007, 26, 1485-1489.

26. Aerts, J.M.; Franciscus, G.; Overkleeft, H.S. Preparation of steroidal aminodeoxy glycosides and disaccharides as anti-inflammatory prodrugs. PCT/NL2008/050379, 18 December 2008.

27. Zall, A.; Kieser, D.; Hoettecke, N.; Naumann, E.C.; Thomaszewski, B.; Schneider, K.; Steinbacher, D.T.; Schubenel, R.; Masur, S.; Baumann, K.; et al. NSAID-Derived $\gamma$-Secretase modulation requires an acidic moiety on the carbazole scaffold. Bioorg. Med. Chem. 2011, 19, 4903-4909.

28. Makino, A.; Kurosaki, K.; Ohmae, M.; Kobayashi, S. Chitinase-Catalyzed Synthesis of Alternatingly N-Deacetylated Chitin: A chitin-chitosan hybrid polysaccharide. Biomacromolecules 2006, 7, 950-957.

29. Huang, Y.; Dey, S.; Zhang, X.; Soennichsen, F.; Garner, P. The Alpha-Helical peptide nucleic acid concept: Merger of peptide secondary structure and codified nucleic acid recognition. J. Am. Chem. Soc. 2004, 126, 4626-4640.

30. Mehta, S.; Meldal, M.; Duus, J.O.; Bock, K. Internally quenched fluorogenic $\alpha$-Helical dimeric peptides and glycopeptides for the evaluation of the effect of glycosylation on the conformation of peptides. J. Chem. Soc. Perkin Trans. 1997, 1365-1374.

31. Puglisi, J.D.; Tinoco, I., Jr. Absorbance melting curves of RNA. Meth. Enzymol. 1989, 180, $304-325$.

Sample Availability: Samples of the compounds PNA 2, PNA 3, PNA 5, PNA 7, PNA 9, PNA 10 and compound 4,7 and 8 are available from the authors.

(C) 2014 by the authors; licensee MDPI, Basel, Switzerland. This article is an open access article distributed under the terms and conditions of the Creative Commons Attribution license (http://creativecommons.org/licenses/by/3.0/). 